\title{
Research on the Production Process of the Equipment Quality Supervision Information Construction
}

\author{
LIANG Feng ${ }^{1, a}$, BAI Hai Wei ${ }^{2, a}$ and Li Qian ${ }^{1, a}$ \\ ${ }^{1}$ Company of Postgraduate Management, the Academy of Equipment, Beijing, China \\ ${ }^{2}$ Department of Equipment Acquisition, the Academy of Equipment, Beijing, China \\ acoolwind850327@sina.com
}

Keywords: Equipment Quality Supervision; Information Construction; Information System; Production Process

\begin{abstract}
With the rapid development of information technology, the production and management of the equipment towards to the direction based on digital, network and intelligent, which promote the revolution through the design instrumentalities, production process and testing technology. Nowadays, a new generation of information weapon equipment gets into the critical period of development and manufacturing. Many digital and information techniques have been used in the production stage of the equipment. How to adapt to military enterprise under the new situation of digital production is faced with new challenges. Therefore, the research on the production process of the equipment quality supervision information construction is necessary.
\end{abstract}

\section{The research status}

Informationization in Equipment production of quality supervision is the modern military industrial enterprises. Military representatives take advantage of information technology and modern management technology combined with manufacturing technology, then applied to military industry and military industry production process in every link of enterprise operation and management. It realized product production process to the enterprise management of digitalization and integration and enhance product development capabilities, manufacturing capabilities, quality assurance ability and management level. Nowadays, many military companies have brought great changes by widely used digital technology, such asset out to build lean design platform, develop the digital prototype, build the 3D model, set up manufacturing execution system, combined with the design, manufacture and technical service. Mainly reflected in the following three aspects:

1. Constructed a new management mode, the information of joint collaboration.

In the process of model production, multiple subordinate enterprises and hundreds of military enterprise realizes the design and manufacture of collaborative productionby using the digital technology and information technology platform. This measure highlights the concentration of resources and technology advantage, improve the efficiency of collaboration and information resources utilization and improve the enterprise overall production efficiency.

2. Promote the new change process is the informationization of equipment manufacturing.

New equipment in the production process in the comprehensive application of information technology to achieve the three dimensional design and collaborative manufacturing, the traditional prototype has been digitized definition, link of design, manufacture, test and inspection has been covered by a large amount of data and information, to improve the quality of weapons and equipment design, manufacture, assembly and efficiency, the equipment production technology achieve a big span.

3. Informatization interaction between the army and enterprise, implements the service in new way.

Make grinders units actively create new technical service means, wide application of information technology to carry out the equipment technical service support, build integrated information system and realize the combination and the multilateral cooperation. all in real time to the diverse needs of security object, automatic statistics, classification and determine the best security solutions, 
implementation of remote detection, remote diagnosis and precise.

4. Informationization process control, promote the new development of quality management.

Under the condition of digital, enterprise through the development of software system, quality management, control points and control elements constraints embedded in the production process. The operation of the automatic control the development and production process, ensuring the quality of the development and production process must be in accordance with the prescribed procedures to carry out the management files, greatly improving the process control ability, effectively improve the process quality. ${ }^{[1]}$

Administration of quality supervision, informationization is quality supervision management theory and digital manufacturing technology combined with the product. It depends on the enterprise built in digital system, integrating of modern information technology, automation technology, advanced manufacturing technology, modern measurement technology and the modern quality management model is an organic whole. Carding quality under the condition of informatization monitoring task and object, control methods and means, its differences with the traditional supervision mode such as table 1.

\begin{tabular}{|c|c|c|}
\hline $\begin{array}{c}\text { Monitor elements } \\
\text { project }\end{array}$ & $\begin{array}{c}\text { Traditional production } \\
\text { environment }\end{array}$ & Digital production environment \\
\hline $\begin{array}{c}\text { controlled } \\
\text { member }\end{array}$ & $\begin{array}{c}\text { drawings, documents, } \\
\text { material object }\end{array}$ & $\begin{array}{c}\text { virtual prototype, electronic files, } \\
\text { physical, three-dimensional model }\end{array}$ \\
\hline control platform & computer & $\begin{array}{c}\text { simulation platform ERP、 PDM、 } \\
\text { MES、OA etc. }\end{array}$ \\
\hline control method & $\begin{array}{c}\text { review and sign, the } \\
\text { actual product to verify }\end{array}$ & $\begin{array}{c}\text { process virtual + milestone node } \\
\text { control, physical verification, review, } \\
\text { and digital }\end{array}$ \\
\hline control message & paper, discrete & $\begin{array}{c}\text { electronic information, centralized } \\
\text { management }\end{array}$ \\
\hline control measure & file, artificial control & process control, information system \\
\hline
\end{tabular}

Table 1 Traditional quality control and quality control equipment production informatization mode comparison

It can be seen from Tab.1, under informatization equipment production quality supervision, the change of the military representative quality supervision pattern is mainly embodied in three aspects: Firstly, the supervision object has changed, by the supervision of product development to the product of digital virtual prototype and physical prototype supervision; Secondly, the methods changed, it is supervision by artificial means of conformance verification to use information on quality forming process and product quality situation, which is automation, digital, network and intelligent monitoring, verification and analysis of supervision; Finally, the happens is a change in the test method for inspection means, from manual to automatic test, supervision, interpretation and generate a report. ${ }^{[2]}$

\section{The problems existing in the informatization construction of equipment production of quality supervision}

1. Solve the problem of connectivity

Connectivity is the important guarantee to realize quality supervision information, due to confidentiality reasons, although Jun Dai Shi and make grinders unit near at hand but not connectivity, information interaction and process control project is taken online-offline-online modes, time lag effect also brings to the general administration of quality supervision information construction.

2. Solve the problem of the quality of information sharing

Most of quality information generated from make grinders units, but as a result make grinders units from their own interests, are still concerns about information sharing, and there is no a set of 
specifications complete quality supervision information system makes the equipment development and production information cannot be real-time sharing, cannot achieve dynamic quality supervision based on the data analysis. This needs us in the top-level plan explicitly quality supervision information and control the content of the process, on the basis of through technical means in quality assurance information real-time on-demand Shared at the same time to protect commercial secrets of the units make grinders. ${ }^{[3]}$

\section{Supervised by quality supervision information system}

\section{Demand analysis}

To carry out quality supervision information system construction, is to eliminate quality supervision efficiency bottleneck, give full play to the needs of the information advantage. Through the work, it can realize the work of quality supervision streamline, digital record and analysis automation. In addition, it can also improve work efficiency and work quality. The research demand is high, the amount of work is large, the study should be based on laws, regulations, standards, to carry out the demand analysis, clarify the work foundation, process, demand, record. Now it has formed the demand analysis report. Jun Dai Shi is mainly put forward the demand analysis in the following four aspects:

(1)information demand to the file

(2)Jun Dai Shi file Shen Qian electronic needs

(3)the demand of the process control information

(4) Jun Dai Shi database requirements

2 System implementation situation

Demand analysis is completed, the joint research to develop the quality supervision information system construction plan, completed the overall architecture design.

Jun Dai Shi based on the existing network platform, the construction of Jun Dai Shi dedicated quality supervision information system, in a system with multiple network system (PDS, ERP, OA, quality, and fine instrument design system) on the documents and data quickly. Subsequently the system can realize Shen Qian task documents and other information, and can be delivered via physical media and more within the data of system implementation in the form of two-way interaction. According to business requirements, the construction of the whole system is composed of enterprise network subsystem and Jun Dai Shi subsystem, the two subsystem independent operation, through the mobile storage medium between mutual transfer of information. ${ }^{[4]}$

Eritencie retroak

systemanchitectone

Mlitaryagert's nom

sketranchitctine

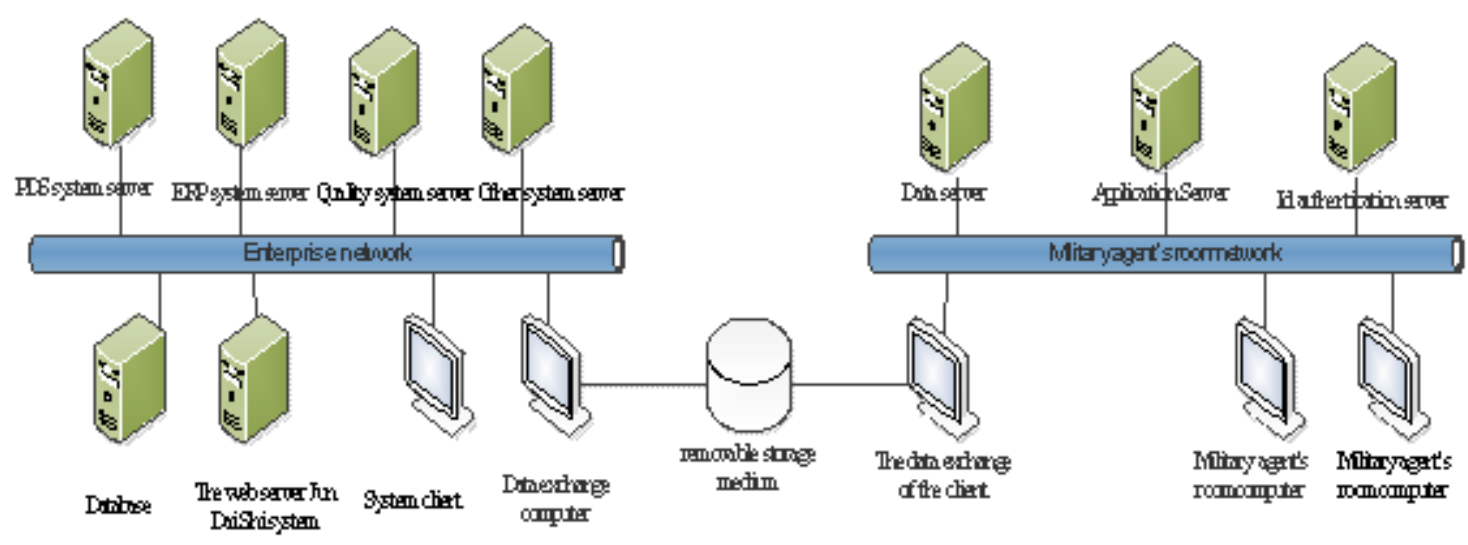

Figure1. Jun Dai Shi quality supervision information system

(1)The enterprise network subsystem architecture

Enterprise network subsystem is responsible for implementing and the interaction between the business enterprise inside various system and provide documents and data collecting and packing output. At the same time, it receives military agent's room points of feedback data, distribution of the corresponding system to the corporate network. 
The service software is responsible for system related to the business enterprise inside the interactive access, complete the following tasks: according to the set cycle performed periodically for PDS, ERP, OA, quality, lean design of enterprise network system in the current need customer control process information and related documents through data comparison, the new data update to the system, form to be exported data. ${ }^{[5]}$ According to the client input conditions, the premise for the document and process information. According to the client the feedback data analysis processing, each customer information will passed to the corresponding enterprise network in the control of the system interface, complete the processing of the control process.

The client software is responsible for the pack will need to export the data from the server side, downloaded to a local form the export file. It can complete the feedback data import, passed to the server to complete the corresponding processing. ${ }^{[6]}$

(2) Jun Dai Shi subsystem architecture

Jun Dai Shi subsystem implementation file view, process control and complete the network subsystem of data exchange with the enterprise. The whole system is consisted by the application server, database server, file server, user authentication server, client, etc.

The database server and file server to complete the data and file storage.

Application server is mainly to complete the data in the system by the import, information query and statistics, and form the feedback data was processed and also provide the user role management and log management and so on. ${ }^{[7]}$

\section{Conclusion}

Equipment quality supervision and information construction of multiple units and departments involved in the military and national defense industry system, must be under the unified leadership and arrange in headquarters. It should under the principle of "overall planning, unified standards, joint construction, connectivity, resource sharing" to build the enterprise digital information quality supervision system of military conditions. ${ }^{[8]}$ Besides, special attention should be paid to the demand analysis, system structure and function of the overall argument, put forward in different stages of the need to control the quality of the elements, such as model contract and special way formally issued and incorporated into the design and production information system of enterprise information. It can make some differences for the quality supervision and the quality of the construction.

\section{Reference}

[1]Yang Cheng-Xian, Zhang Qi, Li Huan-Liang. Theory and Technique of Quality Control in the Production Process of Mechnical Equipment[M].National Defense Industry Press. 2007.06

[2]Wang Jian-Dong, Xie Lian-Song,Zhang Ran.Control and Supervision in the Production Process of Equipment[M]. National Defense Industry Press. 2013.09

[3]Luo Xue-Shan, Luo Ai-Min, Zhang Yao-Hong. The Architecture Technology of $C^{4}$ ISR System [M]. National Defense Industry Press.2010.05

[4]Glossary of Defense Acquisition Acronyms and Terms[EB/OL].Defense Acquisition University Press.2014.07

[5]Zhao Wei-Dong. Smart Business Process Management [M]. Fu Dan University Press2013

[6]Cachon G P, Swinney R. The value of fast fashion: quick response, enhanced design, and strategic consumer behavior. Management Science, 2011,57(4):778-795

[7]Yu Chong-chong, Tan Li. The intelligent information processing technology of monitoring system [M]. China Machine Press. 2013,12 
[8] Qian Hai-hao. Weapon and Equipment Learning Tutorial [M].Beijing: Military and Science 